\title{
Correspondence
}

\section{Less severe mental illness}

Sir: Dr Lacey and Dr Caldicott are quite right (Psychiatric Bulletin, August 1996, 20, 496). The term 'less severe mental illness' has no place in our vocabulary; likewise the term 'minor psychiatric disorder'. 'Minor psychiatric disorder' usually refers to somatic or psychological symptoms of anxiety, mostly seen in general practice which, although unpleasant, are not in themselves seriously incapacitating. However, the cause of such symptoms is usually a major personal conflict, often accompanied by great distress in the family and if these patients are to be helped, they require a great deal of time and skilled work, much more than is usually required for the management of schizophrenia. As well as the illeffects mentioned by Dr Lacey and Dr Caldicott. the use of terms like 'minor' or 'less severe' leads managers to think that no special skdlls need to be provided.

SAMUEl I. COHEN, Emeritus Professor of Psychiatry, University of London

\section{The culture of enquiry}

Sir: A disturbing experience for most psychiatrists has been to hear or read about the deliberations of the latest committee of enquiry through the media. These eponymous reports are often referred to subsequently, in the presumption that their contents are widely known. Unfortunately, this is often not the case. As senior registrars working in the NHS, it might reasonably be assumed that we would be well informed about these. In fact, a common experience among us has been to come upon these informally, if at all. This is clearly not acceptable and means that valuable lessons are not necessarily being disseminated. Another dimension is that these reports and their recommendations have taken on a quasi-legal status and as such. ignorance of their contents is unacceptable.

We suggest that the Royal College of Psychiatrists is ideally placed to ensure that systematic dissemination of these deliberations takes place. One suggestion is that all of these reports should be reviewed in the Psychiatric Bulletin. A precedent for this exists by editorial comment on the Christopher Clunis enquiry in the Bulletin by Coid (1994). Other possibilities include mandating clinical directors of Trusts or tutors to ensure appropriate circulation of reports or at least access to them. There are many benefits from the revolution in the NHS and the delivery of mental health services but one of the biggest dangers of decentralisation and deinstitutionalisation is fragmentation. Whatever solution is found, it is imperative that clinicians are aware of the contents of reports and we urge the College to act on this.

Cord, J. (1994) The Christopher Clunis enquiry. Psychiatric Bulletin. 18, 449-452.

JOHN COONEY, Chairman SR Group, St Bartholomew's Scheme; JAMES WARNER, Lecturer, Royal Free Scheme; JONATHAN HILLMAN, Chairman SR Group, Royal Free Scheme, FARIDA YouSAF, Chairman SR Group. St George's Scheme, PAUL DEWSNAP, Chairman SR Group, Charing Cross \& Westminster Scheme; FRANK KELLY, Chairman SR Group. The Maudsley Scheme, KATRIN EDELMAN, Chairman SR Group, Royal London Scheme, Huw THOMAS, Chairman SR Group, UMDS

\section{The first 12 months of a community support bed unit}

Sir: Philip Thomas and colleagues (Psychiatric Bulletin, August 1996, 20, 455-458) rightly point to the need to distinguish between speciallyfunded 'demonstration projects' and standard services. They suggest that the short-term outcomes of the Maudsley Daily Living Programme (DLP) were possible because of the special status of the DLP, and they argue that the lack of outcome differential in the medium term (at 45 months) was due to the service ceasing to be an intensive 'experimental' service.

The DLP may have been able to bring more intensive staff resources to bear on the psychiatric problems presented by patients than is usually the case in community care, but it was still substantially cheaper in the short term and no more expensive in the medium term than the hospital-based standard services which it sought to replace (in-patient stay followed by out-patient support).

The lack of cost effectiveness for the DLP in the fourth year can probably be attributed to two things. First, DLP staff ceased to have control over in-patient admissions. Second, there was staff demoralisation, linked to the first issue, but perhaps also a consequence of moving from high-profile experimental service to standard, 'mainstream' service. However, it must be stressed that the intensity of staffing in the early 